\title{
ARTIGO
}

DOI: https://doi.org/10.22481/praxis.v14i30.4383

\section{AÇÃO COMUNICATIVA EM HABERMAS E PESQUISA-AÇÃO: DIÁLOGOS PARA FORMAÇÃO NA UNIVERSIDADE}

\author{
COMMUNICATIVE ACTION IN HABERMAS AND ACTION-RESEARCH: \\ DIALOGUES FOR UNIVERSITY TRAINING
}

\section{ACCIÓN COMUNICATIVA EN HABERMAS Y INVESTIGACIÓN-ACCIÓN: DIÁLOGOS PARA FORMACIÓN EN LA UNIVERSIDAD}

Rosana Carla do Nascimento Givigi

Universidade Federal de Sergipe - Brasil

Juliana Nascimento de Alcântara

Universidade Federal de Sergipe - Brasil

Vera Lúcia de Oliveira Ralin

Universidade Federal de Sergipe - Brasil

\begin{abstract}
Resumo: O presente trabalho aborda a universidade enquanto espaço formativo. Tem por objetivo discutir a formação fomentada num grupo de pesquisa a partir do diálogo entre os preceitos da Teoria da Ação Comunicativa de Habermas e da Pesquisa-Ação crítico-colaborativa. Para tanto, as análises partiram do trabalho do XXX da Universidade Federal de Sergipe, que conta com 20 integrantes, desde alunos de iniciação cientifica até alunos de pós-graduação. A formação nesse grupo ocorre segundo o tripé: supervisões, grupos de estudos e trabalho em campo. Como resultados, apontam-se algumas estratégias formativas, tais como a garantia de acesso ao discurso teórico-epistemológico; a necessidade de efetiva participação em grupos de pesquisa e atividades de extensão; o acompanhamento assistido em atividades práticas; o enaltecimento da práxis, com articulações profícuas entre ações e sua deliberada relação com os aspectos teóricos imanentes.
\end{abstract}

Palavras-chave: Formação. Pesquisa-ação crítico-colaborativa. Teoria da Ação Comunicativa.

\begin{abstract}
The present work approaches the university as a formative space. It aims to discuss the formation fostered in a research group based on the dialogue between the precepts of Habermas's Theory of Communicative Action and Critical-collaborative Action-Research. To do so, the analyzes were based on the work of the XXX of the Federal University of Sergipe, which has 20 members, from students of scientific initiation to postgraduate students. Training in this group occurs according to the tripod: supervisions, study groups and field work. As results, we point out some formative strategies, such as the guarantee of access to the theoretical-epistemological discourse; The need for effective participation in research groups and extension activities; Assisted monitoring in practical activities; The exaltation of praxis, with fruitful articulations between actions and their deliberate relationship with immanent theoretical aspects.
\end{abstract}

Keywords: Formation. Critical-collaborative action-research. Theory of Communicative Action. 
Resumen: El presente trabajo aborda la universidad como espacio formativo. Tiene por objetivo discutir la formación fomentada en un grupo de investigación a partir del diálogo entre los preceptos de la Teoría de la Acción Comunicativa de Habermas y de la Investigación-Acción críticocolaborativa. Para ello, los análisis partieron del trabajo del XXX de la Universidad Federal de Sergipe, que cuenta con 20 integrantes, desde alumnos de iniciación científica hasta alumnos de postgrado. La formación en ese grupo ocurre según el trípode: supervisiones, grupos de estudios y trabajo en campo. Como resultados, se apuntan algunas estrategias formativas, tales como la garantía de acceso al discurso teórico-epistemológico; la necesidad de participación efectiva en grupos de investigación y actividades de extensión; el acompañamiento asistido en actividades prácticas; el enaltecimiento de la praxis, con articulaciones provechosas entre acciones y su deliberada relación con los aspectos teóricos inmanentes.

Palabras clave: Entrenamiento. Investigación-acción crítico-colaborativa. Teoría de la Acción Comunicativa.

\section{Introdução}

No discurso de dentro da escola a formação tem sido apontada como uma das principais problemáticas educacionais. Estendendo-se desde as séries iniciais, temos a universidade na outra extremidade, continuando a trajetória que consolida processos fomentados há um longo tempo na esfera da escola básica. De acordo com Morés (2017, p. 142) a prática social da universidade

[...] é definida pela sua instrumentalidade, ou seja, a instituição percebe a divisão social, econômica e política da sociedade em que está inserida, e desse lugar repensa a si mesma, sua função social, com práticas fundadas no reconhecimento público de sua legitimidade e de suas atribuições.

Indubitavelmente a universidade pública carrega consigo condições diferenciadas em comparação aos níveis de ensino que lhe precedem, o que nos leva a inferir que há a necessidade de se definir estratégias políticas e institucionais para atingir objetivos específicos do ensino superior. Em se tratando de uma formação que abraça enquanto público-alvo jovens e adultos, falamos numa formação que preconiza uma verdadeira responsabilização de seus atores. Assim, a formação alça um novo lugar. A função do ensino superior abriga a construção do conhecimento, a delimitação curricular e as práticas pedagógicas inerentes, no entanto, sua função não se encerra nestes aspectos.

Atestamos a ressiginificação da Educação Superior nos últimos anos, vide políticas públicas implementadas que atendem aos interesses do capital, a uma vertente massivamente mercadológica. Dentre tais medidas implementadas, poder-se-ia destacar: a lei 10.861/04, que instituiu o SINAES; a lei 11.096/05, que implementa o PROUNI - Universidade para Todos; o PL 7.200/06, que trata da reforma universitária; o decreto-lei 6.096, que institui o Programa 
de Apoio a Planos de Reestruturação e Expansão das Universidades Federais (BRASIL, 2010).

Deste modo, o nível superior deslocou-se para um lugar de objeto de consumo e passou a ser compreendido como propulsor de crescimento econômico, rentabilidade e status social. Visualizamos a massificação do ensino superior, que provocou sérias dificuldades quanto à garantia da qualidade da formação.

Olhando sob esse prisma, há questões bastante amplas que tomam todas as lacunas, o que invisibiliza outros aspectos fundamentais à formação, como a própria especificidade do professor universitário, desde o que concerne a seus saberes fundantes até a própria formação do ser docente (MOROSINI, 2001; PIMENTA, ANASTASIOU, 2002).

De acordo com Chauí (2003) a formação deve envolver uma relação do passado com o presente, da passagem do instituído ao instituinte. Trata-se de uma obra de pensamento em que há reflexão, crítica, problematização e, por conseguinte, torna-nos capazes de elevar questões ao plano do conceito. Portanto, todos os docentes e pesquisadores deveriam preocupar-se com a formação.

Tais pilares, entretanto, não são independentes entre si, a relação que possuem é de interdependência, de mutualidade e afetamento. Assim, preza-se pela busca de espaços de interação entre o aluno aprendente e a universidade, numa formação que tivesse em seu cerne um processo de apropriação do conhecimento com vistas ao entrelaçamento das dimensões pessoais e profissionais. Ademais, a universidade deveria estar comprometida com a construção do saber, com o avanço da ciência e a propagação da cultura. Mediante esse entendimento, faz-se necessário advogar pela relação ensino, pesquisa e extensão, unindo os campos de conhecimento (ASSIS, BONIFÁCIO, 2011).

Conceber esse tripé consiste numa tarefa deveras complexa, pois depende de uma série de condições institucionais, que vão desde a qualificação do professor até as questões relacionadas a financiamento, por exemplo. Enquanto instituição formadora, a universidade não pode se isentar de pensar recorrentemente sobre essas questões que assolam os princípios de sua função pública, ao acompanhar as mudanças sociais que se dão, redimensionando seu papel.

Assim, o presente trabalho tem por objetivo discutir a formação na universidade a partir do diálogo entre os preceitos da Teoria da Ação Comunicativa de Habermas e da Pesquisa-Ação crítico-colaborativa. 


\section{Que proposta de formação elegemos?}

Estivemos debruçados sobre a formação de alunos da graduação em Fonoaudiologia e, mais recentemente, da Pós-Graduação em Educação, envolvidos nas angústias, tensões e desafios da docência e da pesquisa. A filiação coaduna-se aos preceitos de uma formação reflexiva, crítica e problematizadora, que busca a emancipação dos sujeitos envolvidos nesse processo.

Nesse sentido, anunciam-se alguns apontamentos desafiadores: preparar profissionais para uma prática reflexivo-crítica; formar profissionais investigadores; criar espaços de socialização de conhecimento; exercitar uma prática emancipatória. Em resposta a esses desafios, o caminho é a recuperação de sujeitos pensantes, pela via do conhecimento (ZEMELMAN, 2004).

Logo, a formação acadêmica precisa priorizar o caráter indissociável teoria-prática, com a tônica recaindo sobre o planejamento da formação, partindo de demandas reais, ações práticas e questões epistemológicas. Partindo do princípio de que para formar alguém há a necessidade de correlacionar teoria e prática, no sentido da práxis pedagógica, e para tanto o docente precisaria ter vivenciado essa prática.

Superar a dicotomia teoria-prática, correlacionando-as de forma dialética, torna-se valor fundante para que se pense a formação do aluno no ensino superior. Nesse ajuste, teoria e prática são dimensões valorizadas numa relação onde uma alimenta a outra. Para VeigaNeto $(2003$, p.4)

[...] sem um esquema ou arcabouço teórico, isso que chamamos mundo das práticas - ou, simplesmente, práticas - não faz nenhum sentido e, assim, nem é mesmo observado ou visto e nem, muito menos medido ou registrado. Inversamente, se dá o mesmo: sem alguma experiência, algum acontecimento nisso que chamamos mundo das práticas, não há como pensar, formular ou desenvolver uma ou mais teorias.

As formações no ensino superior têm sido equiparadas, muitas vezes, à formação evidenciada nos cursos de curta duração, aperfeiçoamento, com graduação e pós-graduação intrinsecamente articuladas à dimensão técnica, pragmática das questões, com enfoque instrumentalizador, porém, pouco voltado ao pensamento verdadeiramente científicoepistemológico.

Tomamos enquanto base epistemo-metodológica a pesquisa-ação colaborativo-crítica. O nosso grupo de pesquisa nomeado GEPELC (Grupo de Estudos e Pesquisa em Linguagem e Comunicação Alternativa) iniciou suas atividades em 2008, com atividades que durante esse 
tempo foram se reformulando e com a assunção de novas propostas, circulando entre o campo clínico e o educacional. Integra os grupos do Departamento de Fonoaudiologia e vincula-se ao Programa de Pós-Graduação em Educação (UFS).

O grupo supracitado é composto por professores, alunos de doutorado e mestrado, e alunos de iniciação científica. São 20 pesquisadores envolvidos diretamente. Nasce do encontro com o ensino, nas disciplinas de graduação e se solidifica na pesquisa e extensão. Esse texto se restringirá a discutir a proposta de formação que ocorre no âmbito do grupo de pesquisa.

O grupo de pesquisa é, sobremaneira, um grupo intensivo de estudos. Estes estudos devem promover a construção de conceitos e também a abertura de vontades, de projetos coletivos e individuais.

Árdua tarefa a de nos empurrar para fora de nós mesmos, num tempo onde a corrente parece ser o inverso disso. Tempo de desencontros de ações e de solidão, numa comunicação que não se concretiza, ou que é dita em diferentes idiomas. Por muitas vezes nos vemos na sala de aula falando um idioma estranho aos jovens que lá se encontram. Enquanto professor, estamos em busca de uma comunicação que encontre um entendimento mútuo.

Este é o rompimento com uma compreensão egocêntrica de mundo. Assume-se aqui, então, a proposta da teoria da ação comunicativa de Habermas, que envolve fala e ação na interação de dois ou mais sujeitos que buscam entendimento, que tentam coordenar a ação. Relaciona o mundo objetivo, com o mundo social e o mundo subjetivo.

O conceito de agir comunicativo de Habermas extrapola a racionalidade instrumental. Este conceito foi colhido no interacionismo simbólico de Mead, no conceito de jogos de linguagem de Wittgenstein, na teoria dos atos de fala de Austin e na hermenêutica de Gadamer. A análise e uso deste conceito no trabalho de ser professor nos convoca a uma nova postura, a ação comunicativa e a prática cotidiana vão em busca do entendimento e de uma nova organização, regulada pela ação e também pelo social.

O tempo todo Habermas (1987) nos diz da força da ação, sendo sobreposta ao poder burocrático, assim há a brecha para ações mais produtivas que vençam a patologia social que paralisa a sociedade.

Continuando as estratégias de formação, além de ter como foco o ensino, nossos olhos estiveram voltados para a pesquisa e extensão. Assim, trabalhamos com a ideia de grupo e de ações indissociáveis. Há uma pulverização de conceitos de grupo, aqui a definição de grupo que estará em foco será da participação de todos, a própria ação grupal define como o grupo se organiza, realiza as tarefas, se produz (LANE, 1985). 
Como condição para a existência de um grupo é mister que haja "algo compartilhado" e que este "algo" não dizime as necessidades individuais ou descaracterize as singularidades que o constituem. O que está posto nas abordagens pesquisadas, respeitando suas diferenças, é que o grupo é tanto um espaço de conjunção de singularidades, instância que remete à diversidade de sujeitos, quanto do compartilhado, elo de ligação da pluralidade (ZANELLA; PEREIRA, 2001, p. 4).

O grupo é espaço de negociação, é constituinte dos sujeitos, nele estão presentes as diferenças, a pluralidade é o dispositivo que o mantém entre a harmonia e o conflito, disparando movimentos com fluxos ininterruptos.

Os dados que serviram de base para as reflexões aqui tecidas vêm do trabalho desse grupo. Sustentado pela perspectiva da pesquisa-ação colaborativo-crítica estruturou-se com a pesquisa e extensão. Os projetos envolvem o atendimento fonoaudiológico a pessoas com deficiência, tendo como foco a construção da linguagem e a implementação da Comunicação Alternativa; também são desenvolvidas ações com as famílias e acompanhamentos nas escolas desses sujeitos.

Voltado para as questões da Linguagem/Comunicação Alternativa, o grupo se reúne semanalmente em encontros de 4 horas em média, onde se discutem os casos atendidos, as ações com a família e o trabalho nas escolas. Nesses encontros o que se deseja é "manter a abertura ao outro, salvaguardar o sentimento de identidade comum, consolidar e tonificar a compreensão do outro" (MORIN, 2005, 104).

A formação de um grupo é um movimento permanente, embora seja necessário uma disponibilidade pessoal. O ponto crucial do grupo são as mobilizações coletivas, é preciso que os participantes sintam-se partes e que assumam representação de todos. O grupo vai se formando constantemente no movimento de colaboração. Não há hierarquização do poder, todos devem ter seu reconhecimento na tensão entre as particularidades e o desenvolvimento da coletividade. Na prática não é fácil constituir esse espaço, a todo o momento circulam outros movimentos, como, por exemplo, os relacionamentos preferenciais. Esses não são, a priori, destituintes do movimento grupal, mas precisam ser tratados com cuidado, para que a cumplicidade estabelecida não forme espaços "guetos".

Desses encontros semanais surgiam as demandas de formação. Algumas percebidas por todos, outras pelos membros mais experientes, que na maioria das vezes se representavam pelos professores, ou alunos já formados na graduação, ou de mestrado e doutorado. Não significa que por vezes outros não pudessem ocupar esse lugar. 
Algumas coisas pareciam reforçar o sentimento de grupo, destacam-se a partilha de um objetivo comum, e a relação com a profissão. Os participantes relacionavam-se com informalidade e havia a preservação de uma relação amistosa, durante o tempo de convivência iam sendo criadas as regras, algumas explicitas outras implícitas. O diálogo foi o maior investimento. Enquanto facilitadoras tivemos o cuidado em não fugir das polêmicas, mas também de não extremar as questões ainda delicadas.

Garantir o espaço de fala, a análise das ações pareceu-nos a melhor estratégia para a sustentação grupal. Percebe-se que as produções são resultado das relações estabelecidas no grupo. Quanto mais prospectivas forem essas relações, mais brechas se têm para o aparecimento de vontades, para produção de um coletivo. Os interesses particulares precisam ser negociados, sem desmerecer a experiência dos participantes, a forma como agem, como participam. Os embates precisam ser enfrentados e retornar ao grupo em forma de diálogo.

Outra ação de formação que nasceu das demandas dos encontros individuais foram os grupos de estudos, para além da supervisão. Desse modo, poder-se-ia dizer que o grupo de pesquisa pauta atualmente sua formação no seguinte tripé:

Figura 1. Esquema do funcionamento do grupo de pesquisa quanto à formação - tripé de ações.

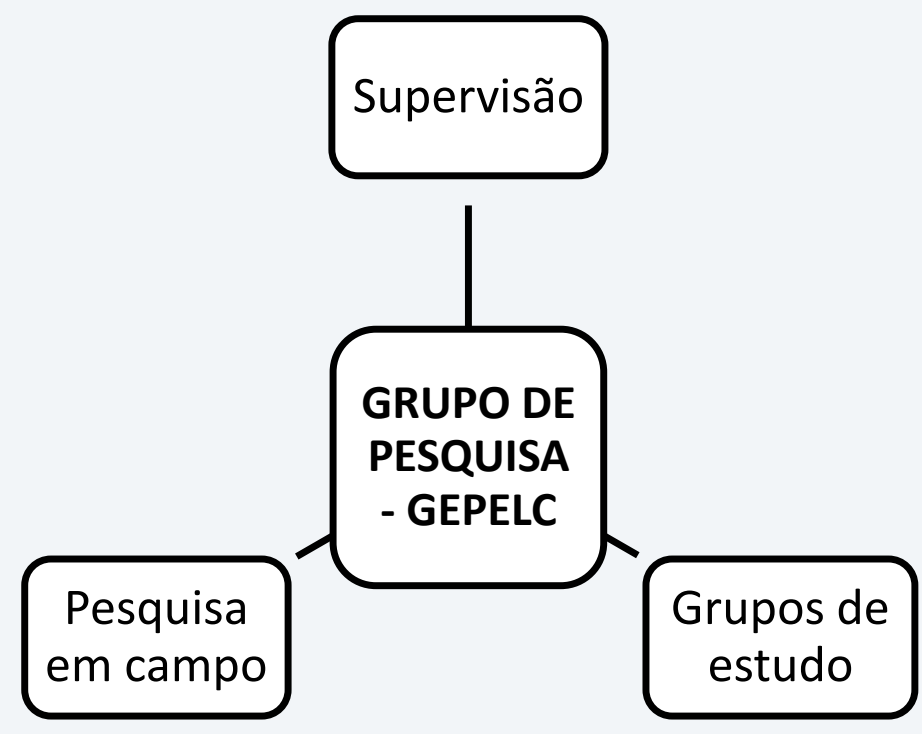

Atualmente, contamos com três vertentes de estudos: 
Quadro 1. Vertentes dos grupos de estudos do GEPELC.

\begin{tabular}{|c|l|}
\hline $\begin{array}{c}\text { FREQUENCIA DO } \\
\text { ESTUDO }\end{array}$ & \multicolumn{1}{c|}{ CARÁTER DO ESTUDO } \\
\hline • Estudo semanal & $\begin{array}{l}\text { Ocorre com todos os componentes, após a supervisão } \\
\text { coletiva realizada às quartas-feiras, que versa sobre temas } \\
\text { voltados à família e à escola. }\end{array}$ \\
\hline - Estudo quinzenal & $\begin{array}{l}\text { Ocorre com a participação de todos, às segundas-feiras, } \\
\text { com temas diversos dentro do espectro da linguagem e da } \\
\text { comunicação alternativa, com ênfase nas bases teóricas, } \\
\text { temáticas estas oriundas das necessidades grupais que vão } \\
\text { sendo tecidas. }\end{array}$ \\
\hline Estudo mensal & $\begin{array}{l}\text { Nasceu de uma demanda dos alunos da pós-graduação, } \\
\text { com o intuito de adensar algumas discussões teórico- } \\
\text { epistemológicas, a partir do debruçamento sobre obras } \\
\text { mais complexas. Acontece dia de quarta, após os estudos } \\
\text { com o grupo maior. }\end{array}$ \\
\hline
\end{tabular}

Muitas ações vão indicando que a formação do coletivo está acontecendo, dentre essas: a vontade de constituir espaços coletivos; a enunciação que é feita em nome de todos; as reorganizações que são feitas cotidianamente; a tomada de decisões que parte de qualquer participante; o cuidado com o outro; o espaço para o conflito; dentre outras.

$\mathrm{Na}$ perspectiva teórica do grupo, o Interacionismo, os estudos enfatizam as bases conceituais; na perspectiva metodológica o olhar se volta para a pesquisa-ação colaborativocrítica e sobre o método clínico-qualitativo; além disso, há a especificidade da Comunicação Alternativa, neste caso as técnicas, métodos, os recursos, o uso do sistema, a construção semiótica e morfossintática, dentre outras.

O trabalho com a comunidade efetiva-se semanalmente, são atendidas pessoas com paralisia cerebral e autismo, destas a maioria faz uso da Comunicação Alternativa, em diferentes estágios. As famílias também são envolvidas através de entrevistas, encontros informais, participação nos atendimentos, visitas domiciliares. Já na escola o trabalho é semanal, o trabalho colaborativo na escola atinge não apenas a pessoa com deficiência, mas os professores, gestores, e colegas de turma. Daí nascem nossas questões de pesquisa e o trabalho de extensão.

Todos os membros do grupo, desde os alunos de iniciação científica aos alunos da pós-graduação, estão necessariamente envolvidos em algum dos eixos de trabalho do grupo. São projetos de extensão, projetos de iniciação científica, tecnológica, e projetos de pesquisa que recaem sobre três linhas principais: a pesquisa clínica sobre autismo, a pesquisa clínica 
sobre paralisia cerebral, e a pesquisa voltada à educação especial nas escolas públicas regulares do estado de Sergipe e municípios da região metropolitana da capital. Para os atendimentos, buscamos a priori a articulação entre alunos iniciados e pesquisadores mais experientes como estratégia formativa para viabilizar um caminho de partilha, colaboração e construção de autonomia.

Dentro do trabalho em campo encontra-se, ainda, o trabalho de formação de professores. Diversas ações já foram desenvolvidas, através de uma parceria com a Secretaria de Educação do Estado de Sergipe e com municípios da Grande Aracaju. Dentre as estratégias estão grupos de discussão; reuniões com professores; palestras; oficinas.

Neste caminho por muitas vezes nos deflagramos com falhas na técnica ou com trabalhos sem consistência epistemológica, era para nós o exercício de instituir uma formação a partir dos construtos do interacionismo. Para tal, as relações colaborativas seriam marcadas pelos 'críticos amigos', onde a crítica é concebida como propositiva, socialmente comprometida com as transformações sociais, como nos diz Habermas. Uma formação comprometida com a emancipação dos sujeitos envolvidos, marcada pela análise constante das práticas e com o estudo teórico.

\section{O grupo de pesquisa como espaço formativo a partir dos pressupostos da pesquisa-ação colaborativo-crítica e da teoria da ação comunicativa em Habermas}

A pesquisa-ação consiste num arcabouço teórico-metodológico marcado pelo compromisso social. Desde sua gênese, num contexto social de pós-guerra ainda marcado pelo método experimental, havia grande demanda de transformação da sociedade, o que se tornaria pilar do eixo epistemológico que sustenta a pesquisa-ação.

A pesquisa-ação colaborativo-crítica demanda dos pesquisadores um interesse mais amplo de não apenas verificar algo, mas de transformar. Uma transformação que necessita interação entre pesquisadores e pessoas pesquisadas e que tem como princípio fundante a declaração que pesquisa e intervenção podem e devem ser trabalhadas paralelamente, quando se almeja a transformação da prática (MATOS; VIEIRA, 2001).

Tal transformação transcende aspectos formais e estruturais, indo ao encontro de uma demanda que se constrói historicamente em opressões do coletivo, tendo por objetivo principal instaurar um processo emancipatório dos sujeitos envolvidos, meta que possui ressonâncias com os princípios formativos defendidos neste estudo. Assim, a pesquisa-ação 
assume caráter de criticidade ao romper com a neutralidade positivista, e esse método vem, portanto, a subsidiar o processo formativo grupal.

Logo, a formação na supervisão e nos estudos acontece de modo que são seguidos os princípios fundantes da pesquisa-ação, segundo nossa filiação. Significando um método de cunho político e participativo, encontramos sustentação num processo em que se estabelecem questões, ações são direcionadas, pessoas são mobilizadas a trabalhar segundo a avaliação crítica dos movimentos.

Todos os atendimentos clínicos, visitas escolares e trabalhos com as famílias são registrados em relatórios descritivo-analíticos e partilhados por/com todos do grupo de pesquisa. Assim, no momento da supervisão, todas as questões são tratadas, problematizadas e pensadas coletivamente. Todos devem se envolver em todos os processos alçados pelos pares, independentemente de se ter uma ação e intervenção sobre eles de forma direta ou indireta. Assim constituímo-nos "críticos amigos".

É válido ressaltar que, embora haja na configuração dos lugares no grupo de pesquisa um mediador principal, líder do grupo, as relações vão sendo estabelecidas da forma mais horizontalidade quanto possível, com discursos e práticas de todos sendo valorizadas e tomadas. A possível hierarquia de posições devido aos percursos acadêmicos não determina lugares estanques, todos são convocados a assumirem a corresponsabilidade pelos processos instaurados e contribuírem colaborativamente, com os pares. Significa, então, advogar por práticas educativas envolvidas na relação professor-aluno com "vazantes de liberdade", valorizando criações livres e movimentos que visam à autonomia, pelo entendimento de que não se pode controlar efeitos, mas envolver-se nesse processo enaltecendo a imprevisibilidade (GIVIGI, 2007, p.65).

Agir nessa perspectiva é tarefa complexa, mas tem se mostrado prospectiva em termos de formação. As práticas destacadas não mascaram as dificuldades pertinentes ao processo construído. No entanto, as possibilidade de sentido e significação dos movimentos vão permitindo que nos distanciemos de práticas estanques, mecânicas, irrefletidas, altamente objetivas, neutras, reducionistas. Podemos vislumbrar, assim, um sentido mais amplo da construção do conhecimento, fundado nas relações discursivas que se amalgamam.

Deslocando-se do nível de mero agrupamento para constituir-se grupo, temos no bojo das relações objetivos comuns que vão sendo delineados e a busca pelo entendimento torna-se fundante para que alcancemos reflexões e ações pertinentes aos problemas que se colocam e carecem de ser pensados a fim de que se promova mudanças. Nessa trama, organizamo-nos 
para possibilidades de ação, assentados na formação crítico-reflexiva, adentrando o agir comunicativo, pedagogicamente emancipatório.

No movimento da formação do aluno através da ação do grupo de pesquisa, seguimos os preceitos metodológicos da pesquisa-ação coadunados aos pressupostos habermasianos do agir comunicativo. O esquema em destaque fora proposto por Barbier (2002) e confere o rigor metodológico da perspectiva. Didaticamente o trazemos para destrinchar os modos de funcionamento da formação em nossa pesquisa:

Figura 2. Esquema construído baseado na espiral cíclica do método da pesquisa-ação definido por René Barbier.

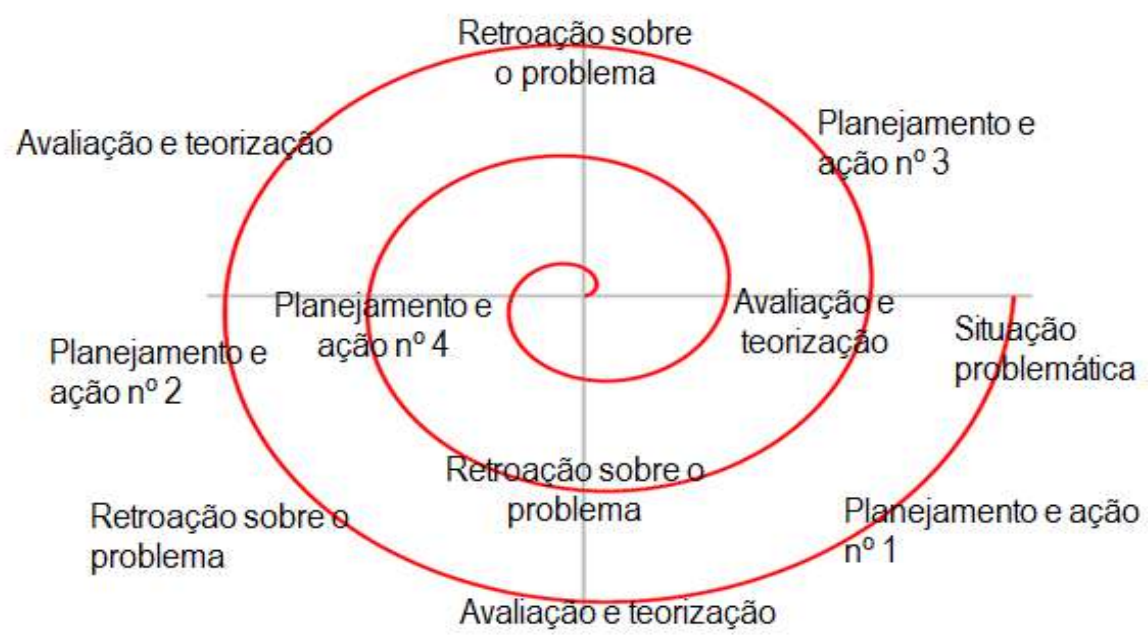

Amparados nessa espiral cíclica que, como se observa, não tem final delimitado, pois segue o movimento do processo, agimos sinteticamente da seguinte forma pensado a formação no grupo de pesquisa, aliando tais princípios da pesquisa-ação aos pressupostos do agir comunicativo habermasiano. Traremos ainda exemplos que ilustrem o processo formativo em questão.

Quadro 2. Quadro explicativo e ilustrativo do trabalho grupal baseado nos pressupostos da pesquisa-ação colaborativo-crítica.

\begin{tabular}{|c|c|c|}
\hline $\begin{array}{l}\text { Momento da } \\
\text { pesquisa-ação }\end{array}$ & Descrição & Exemplo \\
\hline Situação & $\begin{array}{l}\text { Realiza-se profunda imersão no campo } \\
\text { de pesquisa, pautada na observação da } \\
\text { situação problemática, escuta da } \\
\text { demanda dos sujeitos, construção da } \\
\text { implicação do pesquisador junto aos } \\
\text { sujeitos, com comprometimento mútuo }\end{array}$ & $\begin{array}{l}\text { Num contexto de dada escola pública } \\
\text { estadual em que um aluno-pesquisador } \\
\text { acompanha um aluno com deficiência, } \\
\text { realizou-se inicialmente um diagnóstico } \\
\text { institucional com o intuito de conhecer } \\
\text { organização, filosofia, currículo e }\end{array}$ \\
\hline
\end{tabular}




\begin{tabular}{|c|c|c|}
\hline problemática & $\begin{array}{l}\text { em virtude do objetivo comum de } \\
\text { promover mudanças necessárias à } \\
\text { realidade instituída. A situação } \\
\text { problemática sempre deve ser } \\
\text { interpretada pelos sujeitos envolvidos, } \\
\text { é valiosa sua representação. }\end{array}$ & $\begin{array}{l}\text { funcionamento escolar. A partir disso, } \\
\text { delimitou-se junto à equipe escolar a } \\
\text { problemática das estratégias de } \\
\text { avaliação do aluno com deficiência, } \\
\text { problema levantado pela maior parte do } \\
\text { grupo docente. Suas significações foram } \\
\text { escutadas e problematizadas } \\
\text { coletivamente. Depois, fora levada ao } \\
\text { grupo de pesquisa a discussão quanto à } \\
\text { realidade e representações do grupo } \\
\text { escolar, partilhando-se as análises com } \\
\text { os pares, buscando a ampliação das } \\
\text { possibilidades que seriam retomadas no } \\
\text { contexto da escola após o } \\
\text { distanciamento necessário do campo de } \\
\text { pesquisa, a partir dos registros feitos } \\
\text { donde brotaram olhares sob outros } \\
\text { prismas fora do contexto imediato. } \\
\text { Desses diálogos com os pares, } \\
\text { constituindo-se enquanto "críticos } \\
\text { amigos" que procuram pensar sobre o } \\
\text { problema, e pensaram-se estratégias que } \\
\text { poderiam ser vislumbradas junto à } \\
\text { equipe escolar. }\end{array}$ \\
\hline $\begin{array}{l}\text { Planejamento e } \\
\text { ação } 1\end{array}$ & $\begin{array}{l}\text { A partir do diagnóstico minucioso da } \\
\text { realidade estudada, mediante } \\
\text { delineamento junto aos atores do } \\
\text { problema, parte-se para um } \\
\text { planejamento coletivo da primeira } \\
\text { ação voltada à transformação. Para } \\
\text { tanto, podem ser utilizados } \\
\text { instrumentos como entrevistas } \\
\text { individuais, reuniões, grupos focais, a } \\
\text { fim de elaborar planos de ação, com } \\
\text { objetivos e propostas delineadas e } \\
\text { negociadas, que culminarão num } \\
\text { primeiro movimento grupal para } \\
\text { mudança. }\end{array}$ & $\begin{array}{l}\text { Definindo-se o problema supracitado, } \\
\text { aconteceram conversas com professores, } \\
\text { diálogos com a gestão, a fim de elaborar } \\
\text { um primeiro plano de ação que } \\
\text { atendesse suas demandas. } \\
\text { Conjuntamente, traçaram-se objetivos e } \\
\text { definiu-se como primeira ação do grupo } \\
\text { uma reunião em formato de palestra, } \\
\text { com espaço aberto às discussões } \\
\text { oriundas daquela realidade, na qual } \\
\text { outros membros do grupo de pesquisa } \\
\text { trariam elucidações teóricas, amparo nas } \\
\text { políticas públicas em voga sobre o tema } \\
\text { e pontos para discussão grupal, visando } \\
\text { deliberar ferramentas avaliativas mais } \\
\text { prospectivas na educação especial. Junto } \\
\text { aos demais pesquisadores na supervisão, } \\
\text { fora pensada a palestra e seus moldes, } \\
\text { além de aprofundado em grupo de } \\
\text { estudo a apropriação quanto à temática } \\
\text { da avaliação da aprendizagem na } \\
\text { educação especial, traçando-se ideias } \\
\text { para serem levados ao grupo escolar. }\end{array}$ \\
\hline Avaliação & $\begin{array}{l}\text { Após a realização da primeira ação, há } \\
\text { a análise sobre a mesma, avaliam-se } \\
\text { coletivamente os possíveis efeitos } \\
\text { alcançados e reflete-se para que esses } \\
\text { primeiros resultados levem a } \\
\text { teorizações científicas, produzindo } \\
\text { conhecimentos e compreensão a partir } \\
\text { da prática, diante da premissa de que }\end{array}$ & $\begin{array}{l}\text { Após a realização desse encontro entre } \\
\text { escola básica e universidade, os } \\
\text { docentes empreenderiam em suas } \\
\text { práticas pedagógicas os princípios } \\
\text { avaliativos pensados coletivamente e } \\
\text { faríamos juntos a avaliação sobre a } \\
\text { efetividade da ação planejada. Por } \\
\text { conseguinte, fomentara-se a reflexão }\end{array}$ \\
\hline
\end{tabular}




\begin{tabular}{|c|c|c|}
\hline teorização & $\begin{array}{l}\text { os conhecimentos científicos são } \\
\text { provisórios e alocados num dado } \\
\text { contexto histórico/social, reflexões } \\
\text { hauridas no/pelo estudo que irão } \\
\text { ampliar o olhar de pesquisadores e } \\
\text { sujeitos, vide a importância do } \\
\text { processo de heteroformação nesse tipo } \\
\text { de pesquisa. A auto avaliação é } \\
\text { constante no processo e alça o caráter } \\
\text { pedagógico da pesquisa-ação. }\end{array}$ & $\begin{array}{l}\text { individual e grupal quanto às medidas } \\
\text { tomadas e suas ressonâncias no contexto } \\
\text { em questão. Dessas reflexões incitadas } \\
\text { na escola, levou-se para registro } \\
\text { descritivo-analítico o processo, partindo } \\
\text { deste e das discussões a construção de } \\
\text { conhecimentos sobre a realidade } \\
\text { estudada, que subsidiariam ainda as } \\
\text { novas ações, num movimento assentado } \\
\text { na práxis. }\end{array}$ \\
\hline $\begin{array}{l}\text { Retroação } \\
\text { sobre } \\
\text { problema }\end{array}$ & $\begin{array}{l}\text { Diante da avaliação, retroage-se sobre } \\
\text { o problema inicial. Mudanças de } \\
\text { direções e redefinições podem } \\
\text { acontecer, conforme necessidade, pelo } \\
\text { benefício da situação problemática em } \\
\text { questão. É um processo cíclico e assim } \\
\text { vão sendo retomadas as demais etapas, } \\
\text { até que coletivamente se entenda ter } \\
\text { alcançado as mudanças. }\end{array}$ & $\begin{array}{l}\text { Por fim, retomara-se o problema inicial, } \\
\text { na busca por entender os novos } \\
\text { significados atribuídos a ele, para } \\
\text { posterior redimensionamento das ações, } \\
\text { num processo contínuo dentro dessa } \\
\text { sistemática, que não acontece de forma } \\
\text { estanque, mas numa dialética entre cada } \\
\text { movimento. }\end{array}$ \\
\hline
\end{tabular}

Partimos do princípio de que as práticas educativas precisam ser compartilhadas e pensadas de modo imbricado aos processos sociais, históricos e culturais, pois tal formação reflexiva perpassa um alicerce que é co-construído de forma dialética. Assentados nesse modelo, o aluno tende a sentir-se autorizado a se colocar como protagonista em seu processo de aprendizagem, associando muitos de seus conteúdos curriculares à realidade cotidiana dos processos e instituições.

Temos, por conseguinte, pesquisadores coletivos que se constituem dentro da processualidade e complexidade inerente à própria ação coletiva, onde todos os sujeitos somam-se de maneira correspondente. Tal característica amplia a potência de ação, a depender da forma como somos afetados pelas situações instauradas, e fatidicamente anula quaisquer pensamentos de hierarquia ou autoridade fundada na opressão enquanto instrumentos de instituição da coletividade.

Escolher a pesquisa-ação crítico-colaborativa como alicerce para construção do conhecimento, para formação do sujeito na academia, significa adotar uma posição ética que aspira liberdade e, especialmente, tensões provenientes das deliberadas tentativas de horizontalidade e igualdade.

Assentando-nos nesse lugar, concebemos as estruturas através de uma visão não enrijecida, visto que são oriundas das tensões comunicativas que regem os processos dialógicos nessa trama. Assim, o estatuto das estruturas atribuído aqui é de caráter flexível, reflexivo e crítico, conforme anseia uma formação histórico-crítica. 
A coletividade construída na pretensa ausência de neutralidade assume os diálogos travados entre os sujeitos do grupo, levando-os a formarem-se enquanto pesquisadores ativos, transformando o agrupamento num grupo auto reflexivo e ativo na investigação/formação. Desta forma, buscamos mudanças no grupo num movimento endógeno, pelo próprio grupo, assentado em vínculos colaborativos.

Transformarmo-nos em interlocutores ativos congrega com os pressupostos introduzidos por Habermas em sua Teoria da Ação Comunicativa, grupo este chamado por ele de "críticos-amigos". Propõe que, pelo entendimento intersubjetivo mútuo, pela racionalidade, os sujeitos encontram neste espaço proposta privilegiada. Os sentidos do diálogo também são valorizados, assim, aprenderemos a trabalhar com o outro revendo conceitos e paradigmas que não suprem a demanda. O pesquisador se torna crítico-amigo quando é capaz de abandonar sua posição de observador externo, e leva os sujeitos a agirem com mais prudência e autoria no sentido crítico da transformação.

A teoria desenvolvida por Habermas é associada à escola de Frankfurt e tem como ponto norteador a crítica à racionalização proposta pela sociedade industrial moderna. A crítica perpassa a negação que as ciências objetivas fazem à reflexão. Desta forma, ele promove um diálogo constante com autores de uma ampla extensão de linhas teóricas, tais como as contribuições deixadas pelo funcionalismo, pelo marxismo, pela fenomenologia e, até mesmo, a psicanálise.

Desta forma, temos uma teoria que assume um caráter interparadigmático, o que não significa dizer que ele realiza um mero amálgama de toda sorte de linhas teóricas, pois ele produz um processo assentado na riqueza de incorporações/superações, bastante provocativo (PINTO, 1995). Assim, ele propõe um salto paradigmático ao abandonar o paradigma da consciência e assumir um paradigma da comunicação.

Para Habermas (1984) o que há de paradigmático para a racionalidade comunicativa que ele elabora não é a relação de um sujeito solitário, como anteriormente se propunha, com algo no mundo objetivo que pode ser representado, manipulado, mas a relação intersubjetiva à qual ele atribui estatuto fundante - na qual sujeitos falam, atuam, assumem a busca do entendimento entre si quanto a algo que lhes é comum. Esses atores comunicativos agem de acordo com uma linguagem natural, mediante interpretações que são culturalmente apreendidas, referindo-se a algo simultaneamente alocado num mundo objetivo, num mundo social comum e no mundo subjetivo. Logo, sua razão se distingue radicalmente da razão instrumental, racionalidade esta filiada ao empirismo, que marcou profundamente a auto compreensão inerente à era moderna. 
Desse modo, para o filósofo, a razão em meio à linguagem encaminha os entendimentos, na medida em que os sujeitos enveredam pelo conhecimento. Se ganha, então, espaço para a liberdade, a qual só pode ser entendida no jogo da linguagem, enquanto reconhecimento do sujeito e de seus pares. As relações intersubjetivas provocam a reflexão e crítica para se chegar ao consenso da comunicação (DEVECHI, 2010). Os objetivos individuais estão sempre articulados a um objetivo maior, que é, primeiramente, a busca pela negociação da definição de uma situação comum.

Nesse âmbito vemos a estreita relação e influência Habermasiana no princípio colaborativo-crítico da pesquisa-ação, pois sua teoria pressupõe o abandono da relação cognitiva sujeito-objeto ao introduzir uma dinâmica cognitiva de natureza intersubjetiva, enfatizando uma relação sujeito-outro-sujeito que só se torna possível a partir do deslocamento da visão egocêntrica de mundo, dominante até então. Não há verdades últimas, apenas consensos de cunho provisório.

Assim, poder-se-ia dizer do embasamento epistemológico que pode ser tomado pela pesquisa-ação colaborativo-crítica na teoria do agir comunicativo de Habermas, especialmente a partir da década de 1980, ao aglutinar os pressupostos da perspectiva dialética mediante a incorporação desses fundamentos da teoria crítica habermasiana. Entre os principais expoentes da pesquisa-ação podemos citar Wilfred Carr e Stephen Kemmis, que estão situados como principais nomes na perspectiva crítica da pesquisa-ação, e abordam a questão teórica da pesquisa-ação pela perspectiva da relação entre teoria e prática, que têm seus argumentos apoiados nos autores da Escola de Frankfurt, com tônica sobre Jurgen Habermas.

Ele desenvolve a teoria sobre os interesses que orientam os processos de elaboração do conhecimento, sustentando a ideia de que se o processo de produção de conhecimentos não se reduz as técnicas e procedimentos, que se coaduna aos princípios da pesquisa-ação nesta perspectiva supracitada.

Habermas (1987) nos diz que há um interesse crítico-emancipador que tem origem nas ciências crítico-dialéticas. Seu método é a reflexão, que se organiza para desenvolver a crítica e alimentar a práxis. A pesquisa-ação crítico-emancipatória sustenta-se nesse enfoque, no qual estabelece uma relação interacional, crítica e socialmente construída entre sujeito-objeto. $\mathrm{O}$ poder da emancipação está no grupo e é guiada por interesses coletivos. (ALMEIDA, 2010, P. 95).

E como se constroem as relações? Na teoria habermasiana a interação está indicada como ação comunicativa, que é necessariamente mediada. Na interação figura-se a esperança do entendimento e constatação, por dois sujeitos ou mais. O que implica em sentidos e 
significados que são compartilhados e que levam a um consenso no diálogo. Analogamente, nesta perspectiva da pesquisa-ação as relações entre os participantes ocorrem a partir da interação e da parceria, com ênfase na crítica construída coletivamente.

A partir dessas noções, a ação comunicativa é entendida como

[...] aquela forma de interação social em que os planos de ação dos diversos atores ficam coordenados pelo intercâmbio de atos comunicativos, e isso fazendo uma utilização da linguagem (ou das correspondentes manifestações extra verbais) orientadas ao entendimento. (HABERMAS 1987, P. 418).

No entanto, para que o intercâmbio seja orientado ao entendimento, a linguagem deve vir assistida por: verdade, ou seja, que o enunciado seja verdadeiro; retitude, a conformidade com a razão, legitimidade pela argumentação; e veracidade, que é a possibilidade de um enunciado corroborar com as intenções do falante.

A ação, categoria epistemológica fundamental que marca a concepção de ciência nesse grupo de pesquisas, manifesta-se com força transformadora que, tem na práxis eixo fundamental de transformação em critério de verdade e de validade científica. O produto dessas pesquisas se dá na crítica que, revela tensões e conflitos.

\section{Considerações finais}

Ser colaborativo nesse entendimento aqui proposto superou um valor ético para, epistemologicamente, significar uma ação política. No processo formativo, a estratégia metodológica foi a colaboração. Para tanto, compreendemos que para que haja colaboração é necessário que as relações estejam permeadas por afeto. Buscou-se, assim, incitar o engajamento individual em prol do coletivo, numa relação de mútuo afetamento, de dialeticidade. Fora através do estudo, das questões de pesquisa, dos diálogos, que se encontrou o movimento que fortalecia as relações.

O coletivo foi se constituindo marcado pelas singularidades, acolhendo a diversidade que lhes é inerente, convivendo com os conflitos, tensionando as diferenças, buscando a alteridade. Como estratégias formativas pode-se, portanto, apontar a garantia de acesso ao discurso teórico-epistemológico; a necessidade de efetiva participação em grupos de pesquisa e atividades de extensão; o acompanhamento assistido em atividades práticas; o enaltecimento da práxis, com articulações profícuas entre ações e sua deliberada relação com os aspectos teóricos imanentes; a formação pelo viés do fundante tripé ensino/pesquisa/extensão. 
Cabe à universidade, na perspectiva da formação e da democratização, colocar-se contra a exclusão, repensar cotidianamente seu lugar, entendendo a educação superior como direito legítimo do cidadão. Alavancar mecanismos prospectivos de formação do aluno é tarefa que lhe compete, pensar alternativas aos modos engessados de se entender os processos de ensino-aprendizagem é ponto fulcral.

Eleger os princípios da pesquisa-ação colaborativo-crítica e o embasamento epistemológico na teoria da ação comunicativa habermasiana pode provocar rupturas elucidativas nos modos de se pensar o fazer pesquisa, fazer ciência na academia, gerando uma formação mais prospectiva.

Nossas análises não se esgotam aqui, muito ainda há de ser conhecido e problematizado. No entanto, espraiam-se a partir desse estudo possibilidades demarcadas pela assunção do agir comunicativo articulado a um entendimento de formação numa perspectiva pedagógica crítica, confrontando a naturalização embutida no capitalismo, mediante a valorização dos processos dialógicos, potencialmente emancipatórios.

\section{REFERÊNCIAS}

ASSIS, Renata Machado de; BONIFÄCIO, Naiêssa Araújo. A Formação Docente na Universidade: Ensino, Pesquisa e Extensão. Educação e Fronteiras On-Line, Dourados/MS, v.1, n.3, p.36-50, set./dez. 2011.

BARBIER, René. A pesquisa-ação. Tradução por Lucie Didio. Brasília: Plano, 2002. Série Pesquisa em Educação, v.3.

CHAUI, Marilena. A universidade pública sob nova perspectiva. Rev. Bras. Educ., Rio de Janeiro, n. 24, Sept./Dec. 2003.

GIVIGI, Rosana Carla. Nascimento. Tecendo redes, pescando idéias: (re)significando a inclusão nas práticas educativas da escola. 2007. 233f. Tese de Doutorado - Programa de Pós-Graduação em Educação do Centro de Educação da Universidade Federal do Espírito Santo, Vitória, 2007.

HABERMAS, J. The theory of communicative action. Vol 1. Reason and the rationalizalion of society. Boston, Beacon Press, 1984.

HABERMAS, J. Teoria de la accion comunicativa: racionalidad de la acion y racionalizacion social. Version de Manuel Jimenez Redondo. Madrid: Taurus, 1987. v. 1.

LANE, S. T. M.. O processo grupal. In S. T. M. Lane \& W. Codo (Orgs.), Psicologia social: o homem em movimento (2a ed., pp. 78-98). São Paulo: Brasilense, 1985.

MATOS, K, S, L e VIEIRA, S, L. Pesquisa Educacional: O Prazer de conhecer. Fortaleza: Ed. UECE, 2001. 
MORÉS, A. A universidade e sua função social: os avanços da ead e suas contribuições nos processos de ensino e aprendizagem. Revista Reflexão e Ação, Santa Cruz do Sul, v. 25, n. 1, p. 141-159, Jan./Abr. 2017.

MORIN, Edgar. O Método 6: ética. Tradução de Uremir Machado da Silva. Porto Alegre: Sulina, 2005.

MOROSINI, M. C. (org.). Docência universitária e os desafios da realidade nacional. In: Professor do ensino superior: identidade, docência e formação. 2.ed. ampl. Brasília: Plano Editora, 2001.

PINTO, J. M. R. A teoria da ação comunicativa de Jürgen Habermas: conceitos básicos e possibilidades de aplicação à administração escolar. Paidéia (Ribeirão Preto) n $n^{\circ} .8-9$. Ribeirão Preto Feb./Aug. 1995.

VEIGA-NETO, Alfredo. Equívocos ou o (falso) problema da relação entre teoria e prática, na formação docente. Resumo expandido de uma apresentação e discussão na Ulbra, Canoas, 2003.

ZANELLA, Andréa Vieira; PEREIRA, Renata Susan. Constituir-se enquanto grupo: a ação de sujeitos na produção do coletivo. Estud. psicol. (Natal) vol.6 no.1 Natal Jan./June 2001.

ZEMELMAN, H. Sujeito e sentido: considerações sobre a vinculação do sujeito ao conhecimento que constrói. In: SANTOS, B. S. (org). Conhecimento prudente para uma vida decente: um discurso sobre as ciências revisitado. São Paulo: Cortez, 2004.

\section{SOBRE OS AUTORES:}

\section{Rosana Givigi}

Doutora em Educação

Professora da Universidade Federal de Sergipe (UFS). Docente do Programa de PósGraduação em Educação da UFS. Grupos de pesquisa: Grupo de Estudos e Pesquisa em Linguagem e Comunicação Alternativa (GEPELC)/UFS; Educação Especial: abordagens e tendências/ UFES. E-mail: rosanagivigi@uol.com.br

\section{Juliana Alcântara}

Doutoranda em Educação pela Universidade Federal de Sergipe (UFS). Grupo de pesquisa: Grupo de Estudos e Pesquisa em Linguagem e Comunicação Alternativa (GEPECL)/UFS. Email: fga.julianalcantara@gmail.com

\section{Vera Lúcia Ralin}

Doutoranda em Educação pela Universidade Federal de Sergipe (UFS). Grupo de pesquisa: Grupo de Estudos e Pesquisa em Linguagem e Comunicação Alternativa (GEPECL)/UFS. Email: verinharalin@hotmail.com 